\title{
Voice symptoms and handicap in adults with cochlear implants
}

Alessandra Regina da Silva Santos ${ }^{1}$
https://orcid.org/0000-0003-4558-4604
Natasha Gonçalves Leoni Batista ${ }^{1}$
https://orcid.org/0000-0002-1784-6892

Dione Bottentuit da Silva ${ }^{1}$

https://orcid.org/0000-0003-0977-2392

André Luiz Lopes Sampaio ${ }^{2}$

https://orcid.org/0000-0001-7611-1303

Daniela Malta de Souza Medved ${ }^{2}$ https://orcid.org/0000-0003-1637-3234

Ana Cristina Coelho ${ }^{1,2}$ https://orcid.org/0000-0002-0273-4249
Centro Universitário Planalto do Distrito Federal - UNIPLAN, Brasília, Distrito Federal, Brasil.

${ }^{2}$ Hospital Universitário de Brasília - HUB da Universidade de Brasilia - UnB, Brasilia, Distrito Federal, Brasil.

Conflict of interests: Nonexistent

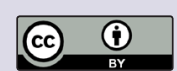

Received on: October 3, 2018 Accepted on: March 1, 2019

Corresponding address: Ana Cristina Coelho

SQNW 108, Bloco J, ap. 105

CEP: 70686-200 - Brasilia, Distrito

Federal, Brasil

E-mail: anacrisccoelho@yahoo.com.br

\section{ABSTRACT}

Purpose: to investigate the presence of vocal symptoms and handicap in adults with cochlear implants, and verify the correlation with their self-perception of the voice quality.

Methods: twenty-seven adults of both genders, with cochlear implants, in the age range of 19 to 57 years participated. The participants answered the self-assessment protocols Voice Handicap Index and Voice Symptom Scale. Furthermore, the participants answered an additional question about how they rated their voices.

Results: for the Voice Handicap Index, the average score was 28.74, in total, and the average score for the Voice Symptom Scale was 29.22, in total. The correlation between the scores of the Voice Handicap Index and the self-perception of the voice showed that the worse the perception, the more handicap in every domain of the protocol. For the Voice Symptoms Scale, the results showed that there is a positive and moderate correlation between the self-perception of the voice and the total scores as well as for the impairment and emotional subscales.

Conclusion: this study verified the presence of handicap and symptoms related to voice, mainly, regarding physical, functional and limitation aspects for the adults with cochlear implants. There is a positive and moderate correlation between the score of the protocols applied and self-evaluation of the vocal quality of the participants.

Keywords: Quality of Life; Self-Assessment; Voice; Hearing Loss; Cochlear Implantation 


\section{INTRODUCTION}

Hearing impairment can compromise the social life of an individual, since it interferes directly in speech and language development, interpersonal communication and learning, interfering with the academic and professional development of the affected person ${ }^{1-3}$. The cochlear implant $(\mathrm{Cl})$ is an effective resource that improves several aspects of quality of life of the individual with hearing impairment. Currently, over 100,000 people worldwide use this device ${ }^{4}$.

Voice and hearing are intimately related. Hearing is a complex and elaborated activity, from detection of sound stimuli by the peripheral organs to its interpretation by the central nervous system. Hearing is, therefore, an important factor for the maintenance of an adequate voice production ${ }^{5}$. Because it plays a key role in the development of oral communication, hearing is essential for the development of the voice ${ }^{6}$.

Voice production involves respiration, phonation, resonance, suprasegmental and articulatory features ${ }^{7}$, and auditory monitoring helps the regulation of these aspects, including duration, fundamental frequency and formants. Auditory monitoring is also important for the neuromuscular control of the organs involved in voice production.

Considering the deaf individual, hearing impairment can be considered an impediment for the normal development of the voice, because it restricts the individual in the reception of the voice and reduces the ability of the speaker to monitor his own voice ${ }^{2,8}$.

The voice characteristics of individuals with hearing impairment can vary according to the type, severity and onset of the hearing loss ${ }^{9}$. Voice alterations cited in the literature include strain, breathiness, monotone, lack of rhythm, decreased intensity, unpleasant quality, hoarseness, vocal fatigue, high pitch, low intonation, loudness with excessive variation, unbalanced resonance, altered respiration, brusque vocal attack and unintelligible articulation ${ }^{10}$. This way, speechlanguage pathologists should regard the voice of individuals with cochlear implantsin terms of evaluation, intervention and self-assessment.

The self-assessment of an individual about a voice problem is a tool to acknowledge voice handicap and symptoms related to the problem, verify the effectiveness of an intervention and develop directive procedures for the clinical practice ${ }^{11}$. The perception of an individual about the voice, as well as the impact of the voice disorder on the quality of life complete the perception of the clinician regarding the severity of the alteration ${ }^{12}$. In patients with $\mathrm{Cl}$, this investigation can influence the therapeutic approach, the awareness of the effects of the voice problem and the confirmation of the efficacy of the treatment ${ }^{13-15}$.

The importance to map the existence and the impression of a voice disorder in individuals with cochlear implants is, therefore, to understand their perspective regarding the voice and the impact of a disorder, and design a therapeutic plan. This way, the clinician can follow the progress, allowing better chance of therapeutic success and individual satisfaction ${ }^{16}$. In a literature search, only one study ${ }^{13}$ approaching this topic was found, in which the Voice Handicap Index was used in an adult population with moderate to profound hearing impairment using hearing aids.

Given the above, the purpose of this study was to investigate the presence of voice handicap and symptoms in adults with cochlear implants and verify their correlation with the self-assessment of the voice quality.

\section{METHODS}

This study was approved by the Ethics Committee for Research with Human Beings of the Centro Universitário do Distrito Federa I - UDF, using the Plataforma Brasil, process number 50409715.3.0000.5650.

To enroll in this study, the participants were contacted by phone, e-mail and social media, and the ones who agreed to participate received the information letter and informed consent form about the study and the guarantee of confidentiality regarding any identification information, according to the guidelines provided by the Resolution 169 of October $10^{\text {th }}$, 1996 of the National Health Council.

Twenty-seven adults of both genders, aged between 19 and 57 years, with pre-lingual or post lingual severe to profound hearing impairment, with cochlear implants participated. There was no differentiation of the participants regarding onset of the hearing impairment, use of unilateral or bilateral $\mathrm{Cl}$, use of a contralateral hearing aid, auditory threshold with the device or any other variables, considering that the purpose of this study was to understand the profile of voice handicap and symptoms of the overall population with Cls.

The inclusion criteria were: age between 18 and 60 years; having the ability to read and interpret the items of the protocols; absence of intellectual or emotional impairment; participation in a rehabilitation program; and hearing experience with the $\mathrm{Cl}$ of at least one year. The exclusion criteria were: current or previous smoking 
habit; daily use of alcoholic beverages; professional voice use; and history of laryngeal disorder.

All of the participants answered the validated version in Brazil of the self-assessment protocols Voice Handicap Index $(\mathrm{VHI})^{17}$ and Voice Symptoms Scale (VoiSS) $^{18}$.

The VHI is a protocol that measures how a voice problem impacts the life of an individual and assesses the aspects of disability, handicap and defect. It consists of 30 items involving three content domains: functional, physical and emotional. The score is calculated by simple summation and can vary from 0 to 120 . The greater the score, the greater the handicap.

The VoiSS brings information about communication difficulties, pharyngeal symptoms and psychosocial distress that a voice problem can cause in the life of an individual. In contains 30 items divided into three subscales: impairment (15 items), emotional response (8 items) and physical symptoms (7 items).

After the guidelines provided by the researchers, the participant filled the protocols in a single appointment. The researchers emphasized that the items should be answered considering only the voice and no other aspects such as auditory skills, speech and language. In addition, the participants responded to the selfassessment item: "Circle how you rate your voice".
The participants rated their voices as excellent (1), very good (2), good (3), fair (4) or poor (5).

The scores of the protocols were charted and submitted to descriptive statistical analysis and correlation with the self-perception of the voice (total scores and scores of each domain). To present the scores, descriptive statistical analysis was performed using the mean, median, mode, standard deviation (SD) and variance values. To study the correlation between the numeric variables, Spearman's correlation for non-parametric data was used. The level of significance of $5 \%$ and the following positive and negative ${ }^{19}$ correlation scales were adopted:

- < 0.2: negligible correlation

- 0.2 to 0.4 : weak correlation

- 0.4 to 0.6: moderate correlation

- 0.6 to 0.8 : strong correlation

- 0.8 : very strong correlation

\section{RESULTS}

Twenty-seven adults aged between 19 and 57 yeas participated. Ten were women (37.04\%) and 17 were men $(62.96 \%)$. The average age of the participants was 37.6 years. The average age for women was 34.6 years, and for men 39.3 years. The mean scores and other measures of central tendency of the VHI and VoiSS are presented in Table 1.

Table 1. Descriptive values of the scores of the self-assessment protocols Voice Handicap Index and Voice Symptoms Scales in adults with cochlear implants

\begin{tabular}{ccccccc}
\hline \multicolumn{2}{c}{ VARIABLES } & MEAN & MEDIAN & MODE & SD & VARIANCE \\
\hline \multirow{6}{*}{ VHI } & TOTAL & 28.74 & 22 & 71 & 20.78 & 431.97 \\
& FUNCTIONAL & 11.15 & 10 & 0 & 8.59 & 73.82 \\
& PHYSICAL & 10.81 & 9 & 9 & 6.40 & 41.00 \\
& EMOCIONAL & 6.78 & 5 & 0 & 7.27 & 52.79 \\
\hline \multirow{4}{*}{ VOISS } & TOTAL & 29.22 & 26 & 30 & 19.15 & 366.72 \\
& IMPAIRMENT & 18.56 & 17 & 15 & 11.76 & 138.33 \\
& PHYSICAL & 5.89 & 5 & 8 & 4.80 & 23.03 \\
& EMOTIONAL & 4.78 & 2 & 0 & 5.87 & 34.41 \\
\hline \multicolumn{2}{l}{ VOCAL SELF PERCEPTION } & 2.63 & 3 & 3 & 1.04 & 1.09 \\
\hline
\end{tabular}

$\mathrm{VHI}=$ Voice Handicap Index

VOISS $=$ Voice Symptom Scale

$\mathrm{SD}=$ Standard Deviation 
Regarding self-perception of the voice, 5 (18.5\%) participants assed their voices as excellent, 5 (18.5\%) as very good, $13(48.1 \%)$ as good, $3(11.1 \%)$ as fair and $1(3.7 \%)$ as poor.

The distribution between the total score of the VHI and the question about self-perception showed that the participants who rated their voices as excellent presented with low score in the VHI, suggesting little or no voice handicap. There was high variation of the scores of the $\mathrm{VHI}$ for the participants who considered their voices to be very good. Only one participant rated the voice as bad, and this participant presented with high score in the protocol (Figure 1).

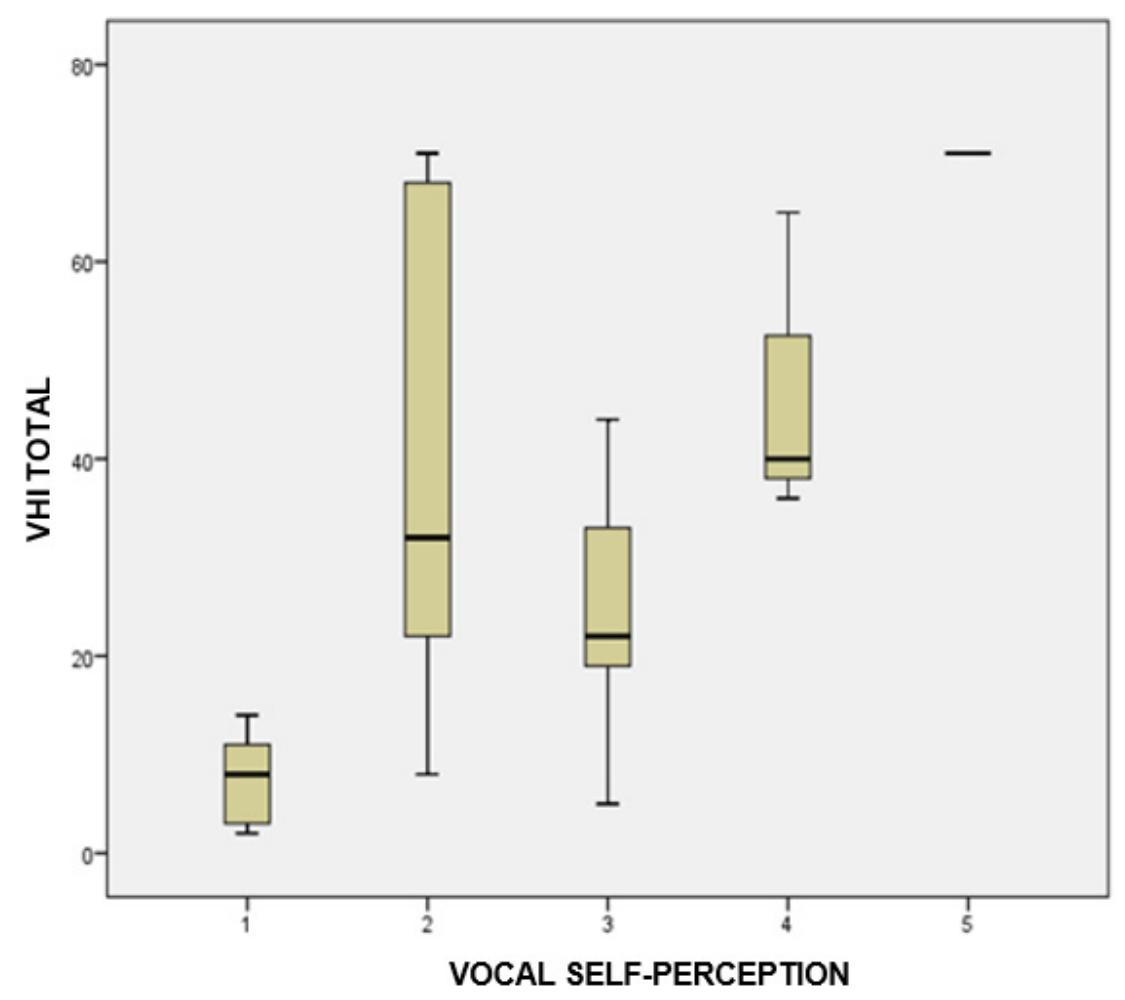

VHI = Voice Handicap Index

Figure 1. Distribution of the total score of the Voice Handicap Index according to the additional question about vocal self-perception

As for the distribution of the total score of the Voiss in relation to the self-perception item, a uniform distribution was verified in all of the categories of the item. There is a tick mark in option 5 of the self-perception scale, because only one person evaluated the voice as "poor". Options '1', '2', and ' 3 ', had outliers, which are individuals whose results did not follow the pattern of the others (Figure 2). 


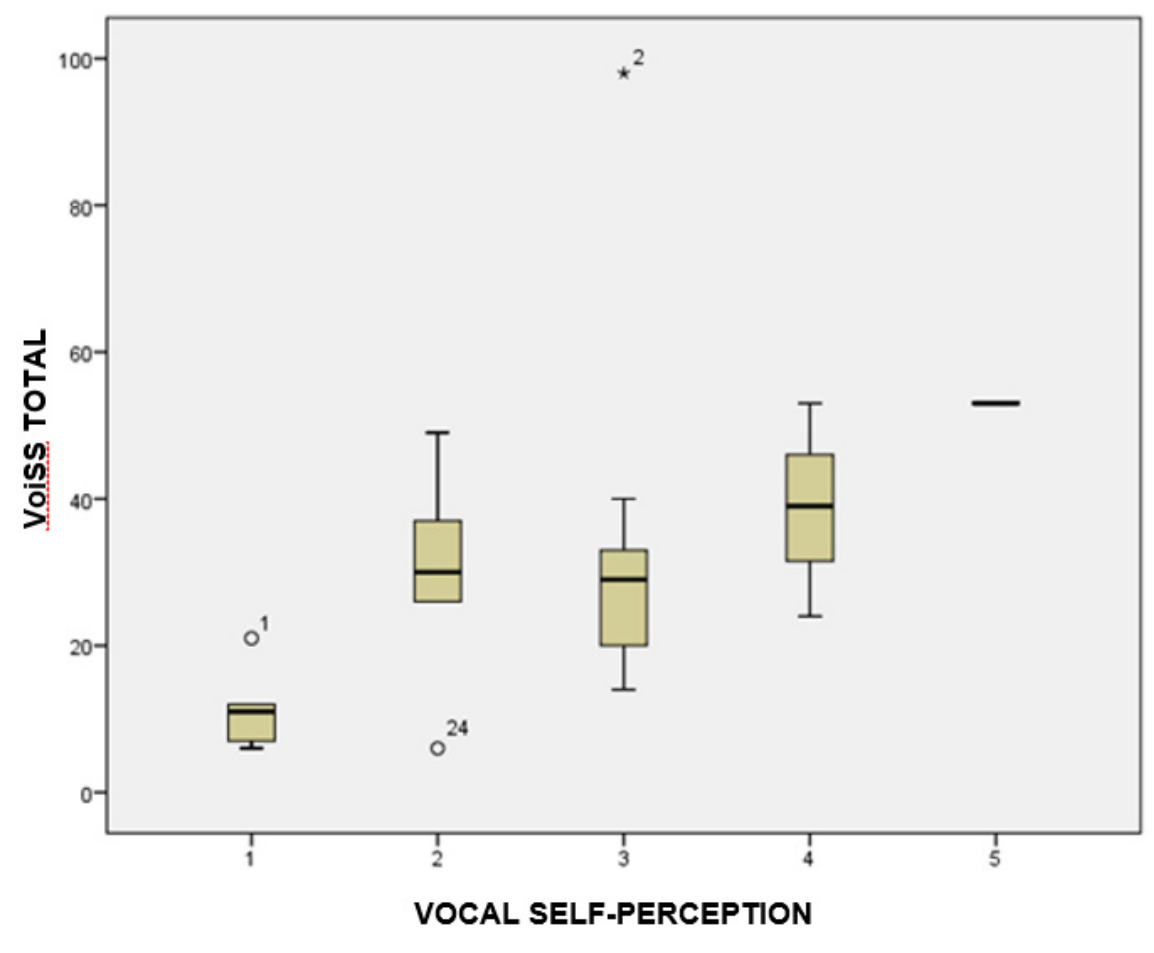

VoiSS $=$ Voice Symptom Scale

Figure 2. Distribution of the total score of the Voice Symptom Scale according to the additional question about vocal self-perception

For the correlation between the self-perception of the voice quality with the scores of the protocols, Spearman's correlation was used. The results indicated positive and moderate correlation between selfperception of the voice and the scores of the VHI. While self-perception of the voice worsened, there was a greater handicap in all domains of $\mathrm{VHI}$ (Table 2).

Table 2. Correlation between the scores of the Voice Handicap Index and the vocal self-perception of adults with cochlear implants

\begin{tabular}{lcc}
\hline & CORRELATION & P \\
\hline TOTAL VHI & 0.533 & $0.004^{\star}$ \\
FUNCTIONAL VHI & 0.477 & $0.012^{\star}$ \\
PHYSICAL VHI & 0.499 & $0.008^{\star}$ \\
EMOTIONAL VHI & 0.469 & $0.014^{*}$ \\
\hline
\end{tabular}

Spearman Correlation Coefficient

$* p \leq 0.05$

$\mathrm{VHI}=$ Voice Handicap Index
Regarding the results of Spearman's correlation between self-perception and the score of the VoiSS, there was a positive and moderate correlation between self-perception of the voice and the total score, impairment and emotional subscales. There was no significant difference between the self-perception and the physical subscale of the VoiSS (Table 3 ).

Table 3. Correlation between the scores of the Voice Symptom Scale and the vocal self-perception of adults with cochlear implants

\begin{tabular}{lcc}
\hline & CORRELATION & P \\
\hline TOTAL VOISS & 0.548 & $0.003^{\star}$ \\
FUNCTIONAL VOISS & 0.550 & $0.003^{\star}$ \\
PHYSICAL VOISS & 0.194 & $0.333^{\star}$ \\
EMOTIONAL VOISS & 0.419 & $0.029^{\star}$ \\
\hline
\end{tabular}

Spearman Correlation Coefficient

* $\mathrm{p} \leq 0.05$

VOISS $=$ Voice Symptom Scale 


\section{DISCUSSION}

Voice is a very important instrument for oral communication, and due to the lack of auditory monitoring, individuals with hearing impairment have poor perception of the voice ${ }^{6}$, causing deviations in the voice quality. The literature shows increasing interest in developing and using result measures based on patient opinion, such as handicap and quality of life indexes, since they attempt to capture the perception of the patient regarding the voice ${ }^{17}$.

This study investigated voice symptoms and handicap in adults with Cls, and analyzed the existence of correlation between these symptoms/handicap and their self-perception of the voice.

Table 1, referring to measures of central tendency, shows mean score of 28.74 for the $\mathrm{VHI}$ and 29.22 for the VoiSS. The study that validated the VHI ${ }^{11,17}$ in Brazil found, for the population with vocal problems, mean scores of 48.1 , in total; 12 for the functional domain; 22.2 for the physical domain; and 13.9 for the emotional domain, with $52 \%$ of the participants evaluating their voices as poor and $48 \%$ as fair. A subsequent study ${ }^{20}$ determined the cutoff value of 19 points for the total score of this instrument, discriminating the scores presented by healthy individuals and individuals with voice problems.

Thus, although it is an empirical comparison, it can be inferred that the studied population with $\mathrm{Cl}$ presents with less voice handicap than the population with voice problems in general, but present with a score that suggest voice handicap in relation to the population without vocal problems, since that the mean score exceeded the cutoff value indicating absence of voice handicap.

The validation study of the VoiSS in Brazil ${ }^{18}$ found the cutoff value of 16 points to differentiate individuals with dysphonia from individuals with healthy voices. The mean scores of the individuals with voice problems were 30.12 for the impairment subscale; 8.85 for emotional response; 10.46 for physical symptoms; and 49.43 in total. These results suggest that, as for the $\mathrm{VHI}$, the users of $\mathrm{Cl}$ present with less symptoms than the population with voice problems, but present with scores that suggest voice symptoms beyond what is considered to be normal.

The domains for which the population of this study had greater scores were the functional and physical domains of the $\mathrm{VHI}$, and the impairment subscale of the VoiSS. This way it is suggested that the population with $\mathrm{Cl}$ perceive certain difficulties with the voice use in daily life and with organic or physical symptoms, but these difficulties do not cause emotional impact ${ }^{21}$.

In this study, there was a positive and moderate correlation between the self-assessment protocols and the self-perception of the voice. It is emphasized that self-perception of voice quality can be influenced by personality and psychological factors ${ }^{22}$, in addition to auditory and kinesthetic factors ${ }^{23}$. In both validation studies $^{17,18}$, the scores of the protocols increase as selfperception of the voice worsens, and this also occurred with the population of this study.

A study $^{13}$ that assessed voice handicap in individuals with hearing impairment with different severities of impairment also evidenced voice complaints in this population. The study compared the results of the hearing impaired individuals and normal hearing individuals and found great variability of responses, but there were statistically significant differences between the groups in all of the $\mathrm{VHI}$ domains, suggesting that voice alteration due to hearing impairment affect functional, physical and emotional aspects. This way, the authors considered that symptoms of a voice problem include not only alterations such as roughness or asthenia, for example, but also other aspects such as lack of auditory monitoring, which influence on its production, and consequently on the life of these patients regarding voice use in daily situations.

The $\mathrm{Cl}$ benefits auditory perception and consequently receptive and expressive language including voice quality. It provides auditory monitoring, improving voice production, and consequently the quality of life of the user, if it is in working condition and the patient well adapted. There are reports about improved measures of noise and perturbation, phonatory control, fundamental frequency, roughness, strain and pitch ${ }^{24}$.

A study ${ }^{25}$ performed with normal-hearing children and children with $\mathrm{Cl}$ showed that implanted children enrolled in rehabilitation programs can present voice characteristics similar to those of normal-hearing children, since voice parameters can be improved by auditory experience provided the auditory monitoring favored by the device.

Even with the use of the $\mathrm{Cl}$, however, it must be considered that some users, specially the pre lingually impaired, may not perceive an alteration, since they always had an inadequate voice model. This does not occur with the dysphonic population with normal hearing who has the experience of an adequate voice model. 
A finding that caught the researcher's attention was regarding the use of the telephone in both protocols. For the item "Do you have problems talking on the telephone?" of the VoiSS, adding the scores of "some of the time", "most of the time", and"all of the time", a total of $66 \%$ of positive answers were obtained. In the $\mathrm{VHI}$, adding the scores of "sometimes", "almost always" and "always", $85.1 \%$ were positive answers. Although the participants were instructed to not consider the hearing problem, this question had the highest scores, suggesting that the participants of this study have difficulties speaking on the phone because the listener may not clearly understand what is said due to deviations in the voice production.

Another relevant finding was that two participants of this study presented with different standards of responses (Figure 1 and Figure 2), since both obtained high scores in the protocols and poor voice self-perception. Whether these individuals could differentiate between speech and voice, if they had good results with the $\mathrm{Cl}$, received adequate speech-language intervention or presented with any laryngeal alteration that could justify the vocal alteration can be questioned.

This study was limited to the application of the protocols and the item about self-perception of the voice quality. In addition to the protocols, future research can, for example, correlate the scores with perceptual and/or acoustic evaluation of the voice and take into account the variables related to the hearing impairment.

Therapy with implanted persons, focus mainly on auditory rehabilitation ${ }^{6}$. It is important, however, that therapists also regard voice of the $\mathrm{Cl}$ user considering the voice characteristics described in the literature, and the presence, even if mild, of voice handicap and symptoms, as observed in this study.

\section{CONCLUSION}

This study verified the presence of symptoms and handicap related to the voice, especially regarding functional, organic and impairment issues in the adult population with cochlear implants. There is a positive and moderate correlation between the scores of the protocols used and the self-assessment of the voice quality of the participants. This way, this study concludes that adults with cochlear implants have few self-reported losses regarding their voice. Nevertheless, there is a need for preventive actions, awareness, guidance and vocal rehabilitation for this population.

\section{REFERENCES}

1. Cacciatore F, Napoli C, Abete P, Marciano E, Triassi M, Rengo F. Quality of life determinants and hearing function in an elderly population: Osservatorio Geriatrico Campano Study Group. Gerontology. 1999;45(6):323-8.

2. Cavadas M, Pereira LD, Behlau M. Disfonia infantil eprocessamento auditivo central. In: Valle MGM (org). Voz: diversos enfoques em fonoaudiologia. Rio de Janeiro: Revinter; 2002. p. 99-109.

3. Battaglini MP, Cecíla BM, de Souza DdG. Desempenho de seleção e nomeação de figuras em crianças com deficiência auditiva com implante coclear. Temas Psicol. 2012;20(1):189-202.

4. Bernardes R. Implante coclear e sua elação com a identidadedo implantado: expectativas e possibilidades. In: Anais do VI Seminário Nacional de Educação Especial; $V$ Encontro de Pesquisadores em educação especial e inclusão escolar; 2014; Universidade Federal de Uberlândia. Uberlândia: Centro de ensino, pesquisa, extensão e atendimento em educação especial; 2014.

5. Buosi MMB. A interdependência entrehabilidades auditivas e produção vocal. Fono Atual. 2002;5(20):53-7.

6. Prado AdC. Principais características da produção vocal do deficiente auditivo. Rev. CEFAC. 2007;9(3):404-10.

7. Nunes RB, Souza AM, Duprat AeC, Silva MA, Costa RC, Paulino JG. Vocal tract analysis in patients with vocal fold nodules, clefts and cysts. Braz J Otorhinolaryngol. 2009;75(2):188-92.

8. de Souza LBR. Differences between vocal parameters of cochlear implanted children and children who use individual sound amplification device. Rev. CEFAC. 2013;15(3):616-21.

9. Behlau M, Thomé R, Azevedo R, Rehder MI, Thomé DC. Disfonias congênitas. In: Behlau M (org). Voz: o livro do especialista.Vol II. 1 ed., São Paulo: Revinter; 2005. p. 1-50.

10. Coelho AC, Bevilacqua MC, Oliveira G, Behlau M. Relação entre voz e percepção de fala em crianças com implante coclear. Pro Fono R. Atual. Cientif. 2009;21(1):7-12.

11. Behlau M, Oliveira G, Santos LeM, Ricarte A. Validação no Brasil de protocolos de auto-avaliação do impacto de uma disfonia. Pro Fono R. Atual. Cientif. 2009;21(4):326-32. 
12. Ugulino AC, Olivera G, Behlau M. Disfonia na percepção do clínico e do paciente. J Soc Bras Fonoaudiol. 2012;24(2):113-8.

13. Madeira FB, Tomita S. Voice Handicap Index Evaluation in patients with moderate to profound bilateral sensorineural hearing loss. Braz $J$ Otorhinolaryngol. 2010;76(1):59-70.

14. Pinto MM. Idade no diagnóstico e no início da intervenção de crianças deficientes auditivas em um serviço público de saúde auditiva brasileiro. Arquivos IntOtorrinolaringol. 2012;16(1):44-9.

15. Costa FP, Yamasaki R, Behlau M. Influence of clinical context in characterization of severity of vocal deviationinfluence of clinical context in characterization of severity of vocal deviation. Audiol Commun Res. 2014;19(1):69-74.

16. Klodsinki D, Fadel CBXF, Costa FM, Santos RS, Rosa MdO, Dassie-Leire AP. Correlation between voice symptoms and auditory-perceptual evaluation of voice in dysphonic individuals. Audiol Commun Res. 2015;20(1):84-7.

17. Behlau M, Alves dos Santos LeM, Oliveira G. Crosscultural adaptation and validation of the voice handicap index into Brazilian Portuguese. J Voice. 2011;25(3):354-9.

18. Moreti F, Zambon F, Oliveira G, Behlau M. Crosscultural adaptation, validation, and cutoff values of the Brazilian version of the Voice Symptom ScaleVoiSS. J Voice. 2014;28(4):458-68.

19. Franzblau AN. A primer of statistics for non-statisticians. Compant HB, editor. New York;1958.

20. Moreti F, Zambon F, Behlau M. Voice symptoms and vocal deviation self-assessment in different types of dysphonia. Codas. 2014;26(4):331-3.

21. Deary IJ, Wilson JA, Carding PN, MacKenzie K. VoiSS: a patient-derived Voice Symptom Scale. J Psychosom Res. 2003;54(5):483-9.

22. Kasama ST, Brasolotto AG. Percepção vocal e qualidade de vida. Pro-Fono R. Atual. Cientif. 2007;19(1):19-28.

23. do Carmo RD, Camargo Z, Nemr K. Relação entre qualidade devida e auto-percepção da qualidade vocal de pacientes laringectomizados totais:estudo piloto. Rev. CEFAC. 2006;8(4):518-28.

24. Coelho AC, Brasolotto AG, Bevilacqua MC. Análise sistemática dos benefícios do uso do implante coclear na produção vocal. J Soc Bras Fonoaudiol. 2012;24(4):395-402.
25. de Souza LB, Bevilacqua MC, Brasolotto AG, Coelho AC. Cochlear implanted children present vocal parameters within normal standards. Int $\mathrm{J}$ Pediatr Otorhinolaryngol. 2012;76(8):1180-3. 